Article

\title{
Experimental Data and Simulations of Performance and Thermal Comfort in a Typical Mediterranean House
}

\author{
Víctor Pérez-Andreu ${ }^{1}$ (D), Carolina Aparicio-Fernández ${ }^{2, *} \mathbb{D}$, José-Luis Vivancos ${ }^{3}$ id and Javier Cárcel-Carrasco $^{4}$ (D) \\ 1 Modelización y Análisis Energético y Estructural en Edificación y Obra Civil Group, \\ Universidad de Castilla-La Mancha, 16002 Cuenca, Spain; Victor.Perez@uclm.es \\ 2 Centro de Investigación de Tecnología de la Edificación, Universitat Politècnica de València, \\ Camino de Vera s/n, 46022 Valencia, Spain \\ 3 Project Management, Innovation and Sustainability Research Center (PRINS), \\ Universitat Politècnica de València, Camino de Vera s/n, 46022 Valencia, Spain; jvivanco@dpi.upv.es \\ 4 Institute of Materials Technology, Universitat Politècnica de València, 46022 Valencia, Spain; \\ fracarc1@csa.upv.es \\ * Correspondence: caap@csa.upv.es; Tel.: +34-963-877-000 (ext. 74586)
}

Citation: Pérez-Andreu, V.; Aparicio-Fernández, C.; Vivancos, J.-L.; Cárcel-Carrasco, J. Experimental Data and Simulations of Performance and Thermal Comfort in a Typical Mediterranean House. Energies 2021, 14, 3311. https://doi.org/10.3390/ en14113311

Academic Editor: Ingrid Martorell

Received: 6 April 2021

Accepted: 2 June 2021

Published: 4 June 2021

Publisher's Note: MDPI stays neutral with regard to jurisdictional claims in published maps and institutional affiliations.

Copyright: (c) 2021 by the authors. Licensee MDPI, Basel, Switzerland. This article is an open access article distributed under the terms and conditions of the Creative Commons Attribution (CC BY) license (https:// creativecommons.org/licenses/by/ $4.0 /)$.

\begin{abstract}
The number of buildings renovated following the introduction of European energyefficiency policy represents a small number of buildings in Spain. So, the main Spanish building stock needs an urgent energy renovation. Using passive strategies is essential, and thermal characterization and predictive tests of the energy-efficiency improvements achieving acceptable levels of comfort for their users are urgently necessary. This study analyzes the energy performance and thermal comfort of the users in a typical Mediterranean dwelling house. A transient simulation has been used to acquire the scope of Spanish standards for its energy rehabilitation, taking into account standard comfort conditions. The work is based on thermal monitoring of the building and a numerical validated model developed in TRNSYS. Energy demands for different models have been calculated considering different passive constructive measures combined with real wind site conditions and the behavior of users related to natural ventilation. This methodology has given us the necessary information to decide the best solution in relation to energy demand and facility of implementation. The thermal comfort for different models is not directly related to energy demand and has allowed checking when and where the measures need to be done.
\end{abstract}

Keywords: building monitoring; efficiency energy performance simulation; thermal comfort

\section{Introduction}

The building sector has consumed $40 \%$ of the energy and produced $36 \%$ of the $\mathrm{CO}_{2}$ emissions of the European Union during 2012. The huge impact of the energy consumption of this sector has made reducing energy use one of the main goals of the European strategies that were established for 2020 for greater energy independence and against climate change. Although in the last few years, the attention regarding the improvement of energy efficiency of buildings has increased, the levels of energy savings that are necessary have not been achieved. Therefore, harnessing the significant energy potential that lies behind buildings remains a major challenge [1].

At the European level, $68 \%$ of the primary energy consumption of the residential sector has been carried out by the climate control needs of the users. In Mediterranean areas, this value is low and is in the range determined by 30\% (Cyprus, Malta, and Portugal) and $50 \%$ (Slovenia and Spain). The rest of the energy consumption produced by the European sector is distributed between $13 \%$ of energy used for producing hot water, $12 \%$ for using appliances, $5 \%$ intended to cook food, and $2 \%$ for lighting the dwellings. As a whole, the ratio of energy consumed by residential households in the European Union countries is approximately between 200 and $300 \mathrm{kWh}$ per $\mathrm{m}^{2}$ [2]. 
In the case of Spain, most of the real state stock was built between 1960 and 2010. Most of the existing homes are located in single-family buildings (70\%). The third part of these dwellings was built before the 1980s [3], and these homes do not have proper energy efficiency. Only 3\% of these dwellings have been refurbished between 2009 and 2013 [4]. The total number of homes built later and until 2019 only represents $1 \%$ of the real estate stock. Energy efficiency standards can produce significant savings for the consumers [5]; however, most of the real estate stock in Spain has been designed without the minimum levels of thermal levels and energy efficiency that are desirable [6]. It is worth mentioning that the average surface area for standard family house in Spain is $75 \mathrm{~m}^{2}$ [7].

In Spain, the first regulations related to energy behavior in buildings started in 1979 [7], which are known as Basic Building Standards (NBE in Spanish). This regulation prescribed a series of constructive solutions for the new buildings without specifying energy consumption limits. The European Directive 2002/91/EU was transposed into Spanish regulations in the first versions, which is known as the Technical Building Code (CTE in Spanish) [8] and the Regulation of Technical Building facilities (RITE in Spanish) [9], as well as in RD 47/2007-Building Energy Certification (CEE) [10]. The implementation of these regulations was effective from late 2007, regulating the construction systems of the envelope and the facilities of the buildings, establishing limits to energy demands and consumption, and the series of procedures that are officially admitted for the energy certification of the energy performance of new buildings [8,9]. Effectively, the mentioned provisions have regulated new buildings since 2008. The subsequent provisions of the European Directive 2010/31/EU became effective in 2014. From then on, the parameters included the almost zero consumption buildings (nZEB) as well as the obligation to build with these characteristics. This period is when the degree of demand for energy behavior of the refurbished buildings was established along with the obligation to certify them before the sale or rental operations.

Based on a study of the existing stock in Spain [11], Spain's long-term strategy for building sector energy renovation prioritizes action for buildings constructed before 1979, which is when legislation on thermal conditions in buildings came into effect [7], and whose energy performance is much lower than presently required [8]. Therefore, residential energy inefficiency is largely attributable to building envelopes lacking the thermal insulation called for by the legislation presently in effect, as observed in studies conducted on samples of buildings in a number of Spanish cities [12]. As a result of the high energy demand generated, minimum comfort standards can only be met with likewise high consumption. Then, the building stock is in urgent need of energy renovation, in which passive improvements should be prioritized. Simulation model (predictive process) assessments of the potential savings in Spain's obsolete building stock based on energy demand calculations have identified pockets of inefficiency and opportunities for savings [13-15].

The thermal comfort evaluation of the users in the building is based on the measurement of the objective physical environmental values such as relative humidity, temperatures, airspeed, etc. It is also based on the knowledge of subjective parameters such as the age, degree of metabolic activity, cognitive processes, and behavior of the users [16]. Among the different existing models for the evaluation of climate comfort, the most accepted are the "steady state" based on standards. To this type of methodology belongs the one provided by the International Standards EN ISO 7730 [17]. This methodology is based on the measurement of values of room temperature, the wet-bulb globe temperature, the relative humidity, the airspeed, and the adoption of parameters at the level of users such as metabolic and clothing rates (coat). The series of environmental and user parameters makes it possible to establish general criteria of thermal comfort based on the calculation of two indicators named the predicted mean vote (PMV) and predicted percent dissatisfied (PPD), which are associated with values of the operating temperature speed of the air and relative humidity [18].

Given the complexity of the thermal, energy, and comfort models that are necessary in order to have a predictive analysis of the thermal behavior of buildings, it is necessary to 
use computer tools that provide reliable results. Thermal and Energy Behavior Simulation (BEPS) programs have proven to be accurate enough to carry out these tasks. Among them, the DOE-2, EnergyPlus, or TRNSYS calculation engines have been widely accepted in the research field [18].

The calculations made with TRNSYS software tools have allowed results with a precision that is needed [19-22] in the following studies. Experimental measurements were performed in Algeria in a typical dwelling using a gas heater in the central corridor as the heating system and were used to calibrate numerical models built with TRNSYS software [23]. The present study calculated the energy savings and thermal comfort improvement. A parametric analysis was performed by varying the location, thickness of thermal insulation, windows, and heating system. Changing the heating system in the studied dwellings, from the central gas heater to the hot water radiators, leads to a reduction of approximately $5 \%$ of gas consumption whatever the envelope performance and decreases the number of discomfort hours more significantly. It was also observed that among the scenarios tested, changing the thermal envelope reduces the heating needs by more than $84 \%$ compared to the reference dwelling, and then, the number of thermal discomfort could be virtually eliminated. Aparicio-Fernández et al. [19] calculated the energy demand of an isolated dwelling dynamically considering the natural ventilation through windows and the infiltrations of the building, which was carried out by performing the energy simulation of the validated model in an annual cycle using the TRNFlow simulation software in TRNSYS.

Regarding the incidence of thermal comfort of the users, the research studies of Sarbu and Pacurar [24] show that interior ventilation in educational centers is key in order to improve the learning and productivity ratios, along with reducing the illness risks of the users. The author concludes that high ventilation rates improve the objective and subjective academic aspects of students, as it increases the attention and concentration of students [25]. On the other hand, the author carried out a study on comfort conditions of the users based on PMV and PPD rates. The study was carried out by using the ASHRAE 55 standard model in an experimental space of an office building. This research compares the energy efficiency of conventional ventilation and an air conditioning system in an experimental space of an office building, using different configurations of the air conditioning systems and control scenarios. This study concludes that all the climate control systems used ensure an increase in thermal comfort. For the calculation of energy consumption and PMV and PDD rates, a simulation model validated with TRNSYS was used.

The published research shows that in Spain, the European Directive 2010/31/EU has not yet had an important impact on the energy efficiency improvement of the existing real estate stock due to the low activity in the sector from the moment of its transposition. In order to achieve a reduction of the energy impact of the construction sector, the strategy in the short and medium term must be directed toward the energy rehabilitation of the existing building batch, previously analyzing the savings potential of latent energy [11].

The main objective of this work is to simulate and analyze the energy performance and comfort during the heating season in a typical house. The work is based on a numerical model of a typical dwelling. Then, different refurbishments are applied to the model in order to improve the energy performance. First, the energy and comfort model of the dwelling developed in TRNSYS is presented in Section 2. The section also describes the calibration process used to validate the model with data obtained from a monitoring campaign. Then, a comprehensive series of refurbishment scenarios is elaborated in Section 3.

\section{Materials and Methods}

\subsection{Building Description}

A building constructed in 1950 is currently located in the orchard area near the city of Valencia. This building is intended to be upgraded for use as a single-family home that can meet the current requirements. This constructed building is a farmhouse/agriculture dwelling formed by a basic construction module based on a traditional Mediterranean 
system. This typology of construction is defined by structural lines with two bays defined by two parallel bearing walls, which at the same time form the enclosure or main façades. It presents a middle beam that is parallel to the main walls and rises on top of these walls in order to form a roof, which rests on two parallel walls. These walls are perpendicular to the façade, closing the envelope and forming the supporting gables for the main beam. The roof is formed with two skirtings of parallel slopes covered with tiles supported on wooden frames. On the ground floor, the house is made up of basic units to accommodate a family and an agricultural garage. The upper floor works as storage for harvest. This type of dwelling is used in spring and summer during the sowing and harvesting periods of vegetables. This type of building is in high demand in the local real estate market as a main residence or for vacation rentals. Furthermore, these buildings are characterized by having a rectangular floor plan. The ground floor consists of a main bedroom, single bedroom, dining area, kitchen, and bathroom [26]. In this current case, the analysis will be executed for a two-story building with an indoor dimension of $9.8 \mathrm{~m} \times 9.5 \mathrm{~m}$, so the ground floor area is $93.1 \mathrm{~m}^{2}$, which nowadays is an usual area for a single-family house. The height on the ground floor is $3.5 \mathrm{~m}$ and the second floor has no constant height, but this space is considered as a storage area without comfort conditions. This current case does not consider the second floor as a living space in order to not exceed the area of a standard home; thus, it is considered as a storage area without comfort conditions. The main entrance is orientated to the east facing the seaside with windows and a big door to access the current garage. In addition, in the west façade, there are some small windows, and in the north and south façade, there are no windows, as can be observed in Figure 1, which shows the current state of the façade. The enclosure of the building is without insulation, as it corresponds to the stock of inefficient energy buildings [13], which are considered in the model. Walls are solid masonry with plasterboard on the inside and cement mortar outside $\left(\mathrm{U}-\mathrm{value}=2.28 \mathrm{~W} / \mathrm{m}^{2} \mathrm{~K}\right)$. The second floor has a gable roof where the area under it is non-habitable; however, it has windows to ventilate this volume and a ceramic surface cover with poor cement mortar and on top covered with ceramic roof tile $\left(\mathrm{U}\right.$-value $\left.=2.65 \mathrm{~W} / \mathrm{m}^{2} \mathrm{~K}\right)$. The floor is solved with pouring concrete on-site, which means directly on the ground without any insulation; then, this concrete is covered with a ceramic floor $\left(\mathrm{U}-\right.$ value $\left.=1.07 \mathrm{~W} / \mathrm{m}^{2} \mathrm{~K}\right)$. The model also considers the horizontal slap that separates the living space and the non-habitable area ( $\mathrm{U}$-value $=1.74 \mathrm{~W} / \mathrm{m}^{2} \mathrm{~K}$ ). In addition, ceramic hollow brick is used for the internal walls (U-value $=2.52 \mathrm{~W} / \mathrm{m}^{2} \mathrm{~K}$ ). Each window has single glass (U-value $\left.=5.7 \mathrm{~W} / \mathrm{m}^{2} \mathrm{~K}\right)$ and a frame with wood $\left(\mathrm{U}\right.$-value $\left.=2.2 \mathrm{~W} / \mathrm{m}^{2} \mathrm{~K}\right)$.

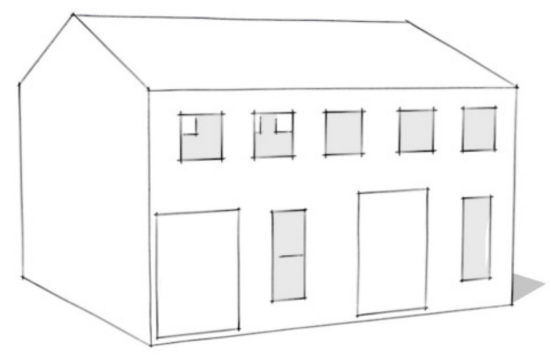

(a)

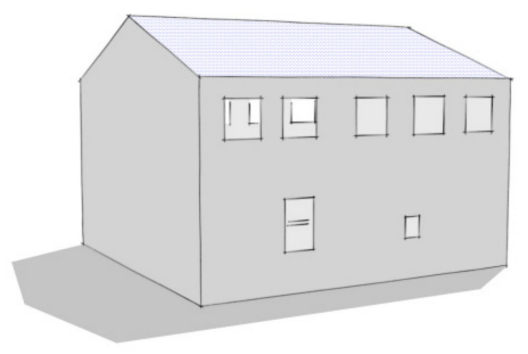

(b)

Figure 1. Model of the building built in Google SketchUp. Current state. (a) South and east façade (b) North and west façade.

Members of the household open the door and windows every day and regularly spends sunny hours outside; the house is closed only at night time.

\subsection{Measurement and Monitoring}

Indoor temperature data were measured with BTH01 high-accuracy temperature and humidity data logger with display humidity (0 to $100 \% \mathrm{RH}$, Accuracy: $\pm 3 \% \mathrm{RH}$ ) and temperature $\left(-35\right.$ to $80{ }^{\circ} \mathrm{C}$, Accuracy: $\left.\pm 0.3{ }^{\circ} \mathrm{C}\right)$. Data were recorded during 56 days, from 
January to March 2017, monitoring 3 different areas. Data were recorded at intervals of $10 \mathrm{~min}$. The measured average indoor temperature is used for calibration and validation of the model developed in TRNSYS. One sensor was site inside the house to evaluate temperatures and humidity on the conditioned area. Non-conditioned spaces were also considered, including the garage on the ground floor and in the area under the roof on the first floor. It is possible to see where sensors were located in Figure 2. Wind direction, wind speed, ambient temperature, and relative humidity were monitored every 10 min by a weather station installed close to the studied building.
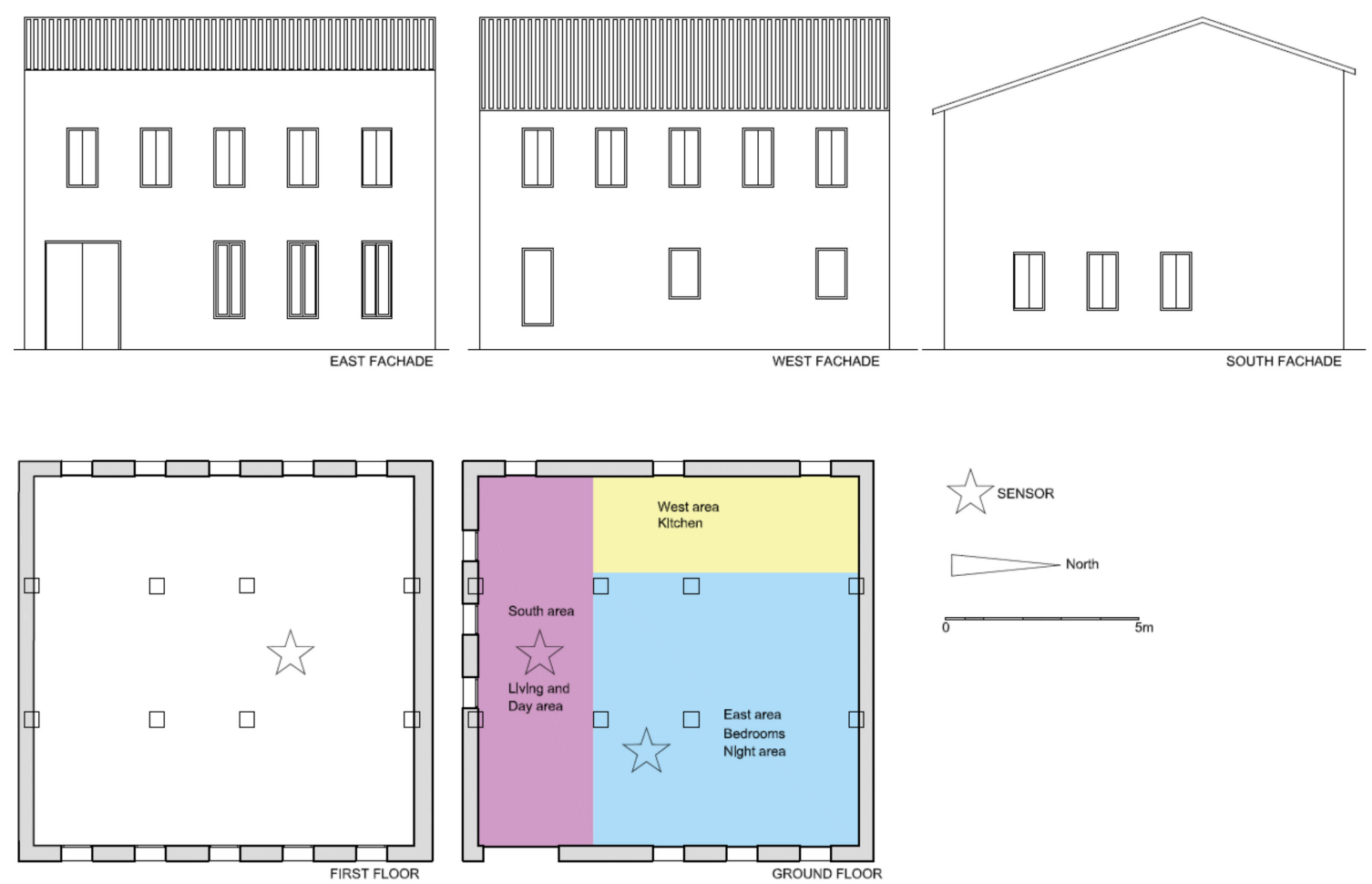

Figure 2. Base model for a house with three different areas: west (kitchen), south, and east (day and night use) for the ground floor, and under the roof for the first floor only with one space.

\section{Simulation Methodology}

\subsection{Simulation Software}

TRNSYS-18 simulation software was used in this study to create a numerical model that predicts and analyzes different parameters of the building in order to refurbish a sock building without any improvement made since it was built. The TRNFlow (TRaNsient Flow) tool was also used to introduce ventilation and infiltration values depending on the external conditions. To estimate energy demand using the TRNSYS tool with data collected on temperature and humidity every $10 \mathrm{~min}$ for a period of less than 3 months has been the main challenge of this work.

\subsection{Model Description}

Google SketchUp is used to create a 3D model of the house; this tool allows generating an idf file with multizone areas and geometric information. Then, a 3D model with an idf file is imported to the TRNSYS program that creates Type-56, which introduces all the information of the building (envelope, occupancy, heating or cooling system, etc.). In order to create a model where wind velocity and direction are considered, Type-56 was replaced by Type-56 TRNFlow, which enables performing natural ventilation and infiltration considering external conditions of wind. In the beginning, infiltration was considered by estimating the cracks and gaps that correspond to this type of building 
lifetime and in previous works [20]. In this case, no blower door test was performed, but similar results would be obtained; for this reason, we have considered an effective leakage area on the ground floor of $0.06 \mathrm{~m}^{2}$ distributed in six openings of $0.1 \times 0.1 \mathrm{~m}$ each.

The first step to validate the model requires introducing collected weather data during the analyzed period using Type-99. This type allows introducing collected weather data to obtain heat demand and temperature that will validate the model for later models. An electric heater is used as the heating system during day and night.

The second step develops the basic scenario using the validated model for a full year through using Meteonorm ${ }^{\circledR}$ Database, exporting into tm 2 format, and using Type- 15 with a $1 \mathrm{~h}$ time step. The second step uses "Model 1" in our work to improve comfort conditions inside the house and reduce energy heat and cool. The ground floor was considered with comfort conditions, and this floor has been divided into three different areas, as shown Figure 2: day use considers the living room (it is the garage in the current house with south orientation); night use considers bedrooms, the work area (it is the living area in the current house with east orientation), and the kitchen with different appliances (it is also the kitchen in the current house with west orientation). In order to define the different spaces, the current structure has been maintained to reduce the interventions costs. Once the spaces have been defined, the thermal loads that occur in the house during a typical week must be defined. The week has been defined with 5 working days and 2 days of weekend holidays. During the week, there are two parameters that do not change: the power of the kitchen appliances connected $3 \mathrm{~h}$ a day and the refrigerator with $329 \mathrm{~W}$ and $12 \mathrm{~W}$ respectively, and the artificial lighting that will be connected when the solar radiation is less than $120 \mathrm{~W} / \mathrm{m}^{2}$ with an active schedule and a load of $2.25 \mathrm{~W} / \mathrm{m}^{2}$. On the other hand, the occupancy will depend on the area analyzed in a standard family house of $93 \mathrm{~m}^{2}$ for 4 people and the type of day, thus, on working days, the bedrooms will be occupied for $7 \mathrm{~h}$ and $9 \mathrm{~h}$ on weekends. The day-use area will be occupied for $13 \mathrm{~h}$ with $50 \%$ of the total occupancy on a workday and maximum occupancy on weekends. The kitchen is used for $4 \mathrm{~h}$ on the weekend and $3 \mathrm{~h}$ on a workday. Control and solar gains were considered through the windows and also the quality of the air considering a minimum of 0.6 renovations per hour for all the spaces.

An important point of this work is to analyze the thermal comfort inside the house using the international standard ISO 7730, which defines the parameters PMV/PPD (Predicted Mean Vote/Predicted Percentage Dissatisfied). To evaluate comfort, it has been necessary to introduce the insulation value of the users' clothing; the value used is 1 clo and 0.5 clo for winter and summer, respectively, as well as 1.2 met for the activity carried out in the house. Thus, on the one hand, the PPD index quantitatively indicates the number of people who will not be comfortable in a given environment, and on the other hand, the PMV index defines an uncomfortable environment when it is above the value 0.5 or below the value -0.5 .

The setpoint for the heating and cooling system inside the building was set between at 21 and $25^{\circ} \mathrm{C}$ through the year in accordance with the RITE regulation established in Spain and also to establish comfort criteria inside of the building [26].

With the base model, several scenarios have been considered in order to minimize the demanded energy to heat or cool the analyzed building on the ground floor:

- $\quad$ Model 1. Base model with current construction considering three different areas for the ground floor, as shown in Figure 2. In this case, no improvement is considered during a full year of results of the current building.

- Model 2. Properties of this model were defined by the Spanish Technical Building Code [8]. The initial model is characterized by very small insulation on its envelope and thus a very large U-value. The transfer coefficient value for the external envelope was reduced by adding insulation. Meeting the current Spanish regulation in Valencia requires fulfilling the next values: for the façade and floor, it is $0.56 \mathrm{~W} / \mathrm{m}^{2} \mathrm{~K}$, the ceiling in contact with a nonconditioned area has a U-value of $0.75 \mathrm{~W} / \mathrm{m}^{2} \mathrm{~K}$, and for windows, (frame plus glass) $2.3 \mathrm{~W} / \mathrm{m}^{2} \mathrm{~K}$ is considered. The thermal properties of the materials in the house envelope and internal walls were taken from Ref. [27]. 
Infiltration through cracks is also limited in the regulation; when the compacity (rate volume/envelope area) is less than 2 , the blower door test at $50 \mathrm{~Pa}$ should give values lower than $6 \mathrm{~h}^{-1}$. In this case, in order to fulfill this requirement, we have to consider six cracks whose square section is $0.1 \times 0.1 \mathrm{~m}$.

- Model 3. To reduce energy demand during winter, more strategies should be performed. For this model, several improvements were considered: window areas of $3 \mathrm{~m}^{2}$ in south orientation are considered to have solar gains in winter; also, in order to control the solar gains during summer, shading devices were set up on this window, and insulation was reinforced considering the extra thickness of $5 \mathrm{~cm}$ on the envelope (walls, ceiling, and floor). The last measure on the global insulation thickness has a high effect on the global heating demand and lower cost; for this reason, it has been considered.

- Model 4. Furthermore, for reducing the demand for cooling energy (only when there is cooling demand), in this model, the natural ventilation has been taken into account; thus, the effect when opening the windows will only be considered if the following conditions are met: when the interior of a house is exceeding $25^{\circ} \mathrm{C}$ and the outside temperature is lower. Indoor ventilation is calculated with TRNSFlow, so the ventilation also depends on the speed and direction of the wind.

\section{Results}

The results obtained during the calibration process and the accuracy of the models developed were calculated with the simulated models. In this section, results for the simulation of the models are presented, considering energy demand and thermal comfort parameters (PPD and PMV).

\subsection{Calibration Results}

Table 1 shows the average monthly temperature and relative humidity, which were calculated with the recorded data in winter; it can be seen that in the living area, temperatures are below the comfort temperatures; therefore it does not meet current requirements for comfort conditions. During the monitoring period, some data were lost through battery discharge, and missing data days were discarded in the analysis; for this reason, there are no data for the garage in March.

Table 1. Recorded data for calibration and validation of the model. Average monthly values for temperature and humidity.

\begin{tabular}{ccccccc}
\hline & \multicolumn{3}{c}{ Temperature $^{\circ}$ C } & \multicolumn{3}{c}{ Relative Humidity \% } \\
\hline & January & February & March & January & February & March \\
\hline East orientation & 13.67 & 16.13 & 16.71 & 67.72 & 69.20 & 70.64 \\
South orientation & 12.58 & 14.69 & - & 71.52 & 69.66 & - \\
Under roof & 10.89 & 13.60 & 14.93 & 78.34 & 75.46 & 75.76 \\
External & 11.48 & 13.24 & 14.50 & 72.64 & 70.18 & 69.74 \\
\hline
\end{tabular}

It is possible to see that instead of a garage, the living area is used, and the temperature is quite low considering comfort parameters, but the data were useful to validate the model. PPD values for the period considered were above $60 \%$ and PMV values were below -1 .

The first step to validate the model requires introducing collected data from the weather during the analyzed period using Type-99. This type allows introducing collected weather data to obtain heat demand and temperature that will enable validating the model for later test models. The model was adjusted with temperature in order to calculate relative humidity depending on the ventilation that we consider. It enables us to define infiltration in different areas of the analyzed house during this period. This process was used in the living area, which is the area that is currently is used to live and has a heating system. Table 2 shows the average monthly temperature and humidity with the validated 
model calculated considering the real construction and situation of the house when data were collected.

Table 2. Calculated data for calibration and validation of the model. Average monthly values for temperature and humidity.

\begin{tabular}{ccccccc}
\hline & \multicolumn{3}{c}{ Temperature $^{\circ} \mathbf{C}$} & \multicolumn{3}{c}{ Relative Humidity \% } \\
\hline & January & February & March & January & February & March \\
\hline East orientation & 13.69 & 16.11 & 16.35 & 69.89 & 66.61 & 69.18 \\
\hline
\end{tabular}

\subsection{Energy Demand}

For analyzing the performance of the house, using transient simulation software and considering wind speed and direction allowed for real results to calculate energy demand for heating and cooling in order to obtain comfort conditions for the four models analyzed. This result lets us know which effect each model has on the energy demand, which is essential to fulfill the current regulations.

In our case, the results obtained in order to condition a family house on the ground floor are summarized in Table 3. The energy demand and the number of hours during which energy is demanded were investigated for each model. Model 1 does not meet Spanish regulation because it demands a large amount of energy for heating and cooling the space; also, the number of hours is quite large: almost during all year, the house is demanding energy to improve the indoor conditions. Model 2 is designed in accordance with Spanish regulations, which significantly reduces the demanded energy, but the number of hours is also quite large. For Model 3 and Model 4, some extra improvements were considered in order to reduce the energy demand. Specifically, for Model 3, in order to reduce the heating demand, two actions were introduced. One window with a global area of $3 \mathrm{~m}^{2}$ is open to the south, and a shadow system is considered in order to control the overheating produced by the insulation. The second action was extra insulation on the envelope to reduce the U-value. These two actions have a direct effect on the energy demand and the number of hours during which it is demanded; therefore, more hours with comfort conditions inside the house without a heating or cooling system have been obtained. For Model 4, in order to reduce the cooling demand, it considers natural ventilation through the windows during summer, spring, and fall. This action can be developed by the users of the house, or an engine can be used to do it; in the last case, extra money is required to do this action. So, energy and hours are reduced during the year for this model as well.

Table 3. Energy demand and number of hours during a year.

\begin{tabular}{ccccc}
\hline & Model 1 & Model 2 & Model 3 & Model 4 \\
\hline Q heat $\left(\mathrm{kWh} / \mathrm{m}^{2}\right.$ year) & 135.19 & 38.16 & 14.88 & 19.55 \\
number of hours & 4848 & 4034 & 2772 & 2960 \\
\hline Q cool $\left(\mathrm{kWh} / \mathrm{m}^{2}\right.$ year $)$ & 47.72 & 29.99 & 25.85 & 13.01 \\
number of hours & 2680 & 3185 & 3007 & 977 \\
\hline Q total $\left(\mathrm{kWh} / \mathrm{m}^{2}\right.$ year) & 182.91 & 68.14 & 40.73 & 32.56 \\
number of hours & 7528 & 7219 & 5774 & 3937 \\
\hline
\end{tabular}

\subsection{Thermal Comfort}

Thermal comfort influence is calculated with parameters PMV/PPD (predicted mean vote/predicted percentage dissatisfied) according to international standard ISO 7730. The PPD index provides a quantitative prediction of the number of people that will be dissatisfied with a certain ambient atmosphere. Figure 3 depicts PPD values for different areas (south, east, and west) and different models represented by a boxplot. Therefore, the data obtained on the PPD index have been divided into quartiles using the boxplot method. Figure 3 shows the minimum value, the first quartile, the median, the third quartile, and 
the maximum value in ascending order in percent for the PPD for each zone and model. The box is defined between the first quartile and the third quartile, so that when the box is larger, it is because there is a greater dispersion between the data of these quartiles. Inside the box, a vertical line indicates the median of the data. The data inside the box are called "lower quartile" and "upper quartile" depending on whether they are before or after the median. Outside the box, the data between the minimum value and the box are called "lower whisker" and those between the box and the maximum value are called "upper whisker" [28].

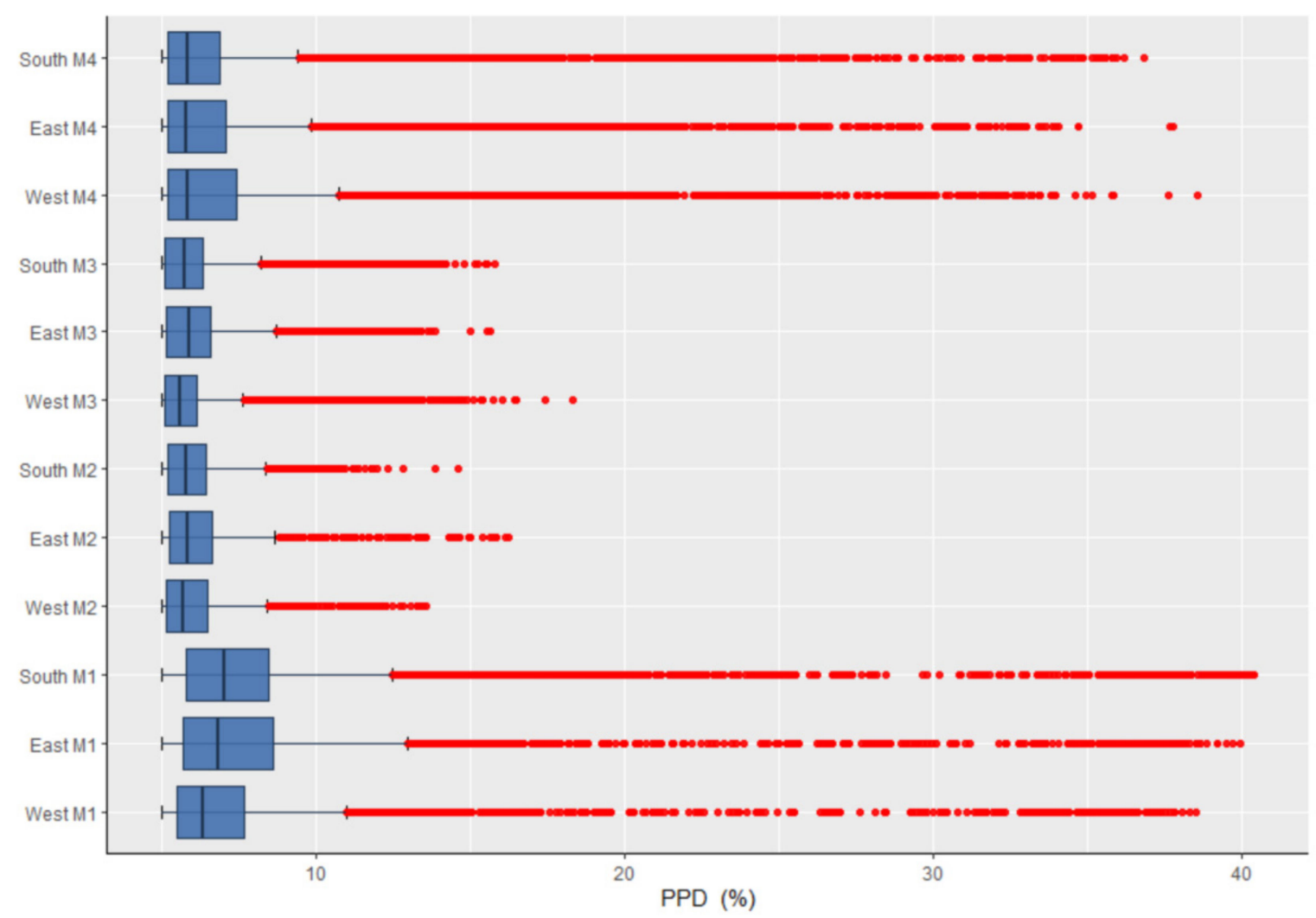

Figure 3. PPD values for different areas (south, east, and west) and different models.

In Model 1, the PPD values were in a desirable PPD range most of the time only in the kitchen. Models 2 and 4 showed that most of the time, PPD values were lower than $18 \%$. Model 3 showed roughly a $95 \%$ confidence interval for the difference in two medians, with PPD values lower than $19 \%$.

The PMV is an index that predicts the average climate assessment value of a large group of people. Whenever the PMV value was above 0.5 or below -0.5 , it was considered as an uncomfortable indoor environment. The PMV value was evaluated with clothing insulation of 1 clo and 0.5 clo during the heating or cooling season (from May to October) respectively, and 1.2 met for activity. Table 4 shows the average PMV values summarized for different areas (south, east and west) and different models. In Model 1, in all areas, an uncomfortable indoor environment was detected. In Models 2 and 4, PMV values showed that most of the time, there was comfort. Model 3 appears to be the best according to the average PMV values for all areas.

In Model 1, PPD values are below 20\%, and PMV values are showing a comfortable indoor environment except for the beginning of the heating season (October) (Figure 4). In Model 2, values are below 20\% throughout the whole year, and PMV values are showing a comfortable indoor environment (Figure 5). In Model 3, PPD values are below 20\% throughout the whole year and PMV values are showing a comfortable indoor environment (Figure 6). In Model 4, PPD values are below 20\% and PMV values are showing 
a comfortable indoor environment throughout the whole year except for the beginning (May) and the end of the cooling season (October), when a 0.5 clo in cooling season was considered. This effect is probably due to the influence of the ventilation on thermal comfort, so a new value of 0.7 clo was considered. Figure 7 shows PPD and PMV values for Model 4 using clo 0.7 in the cooling season; then, a comfortable indoor environment for the whole year was obtained.

Model 1

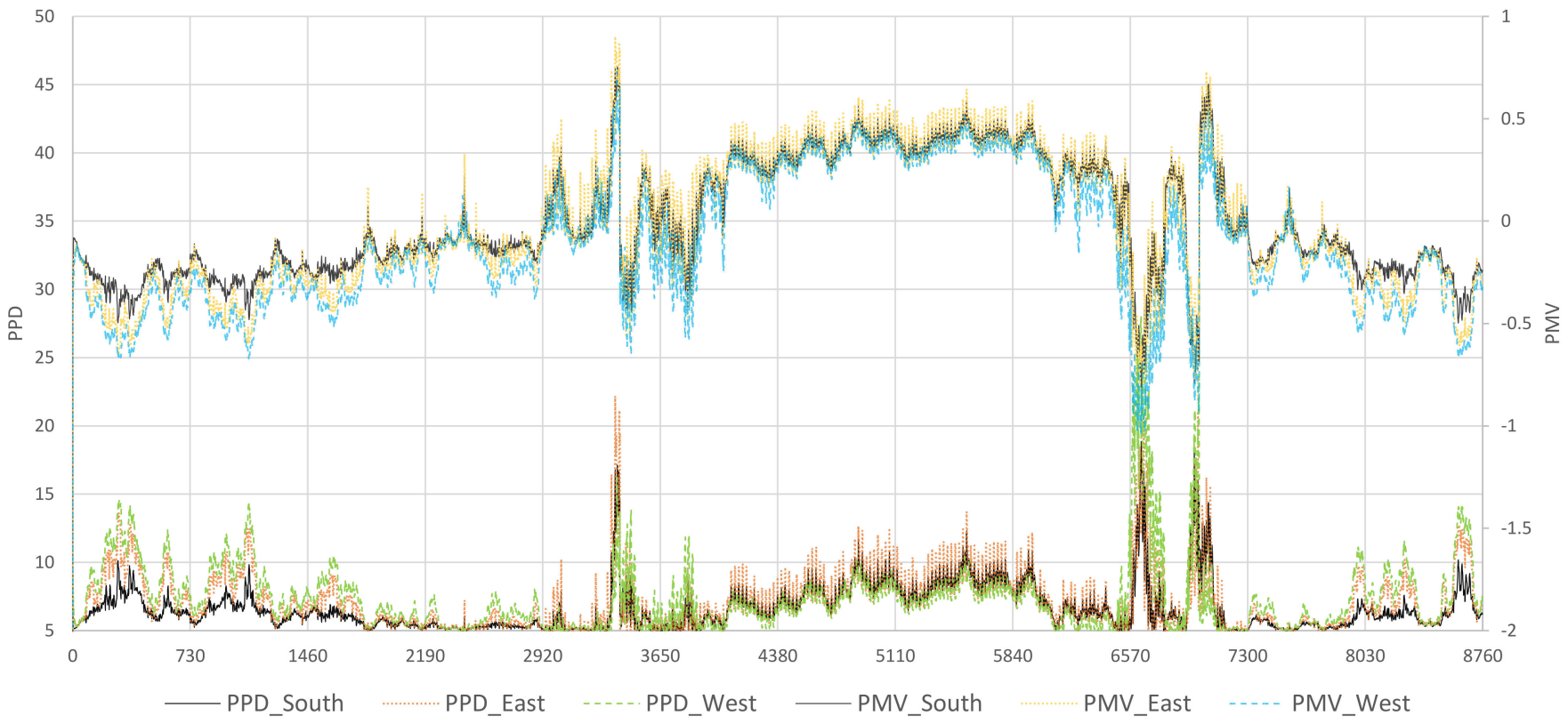

Figure 4. PPD and PMV values for Model 1 in different areas (south, east, and west).

Model 2

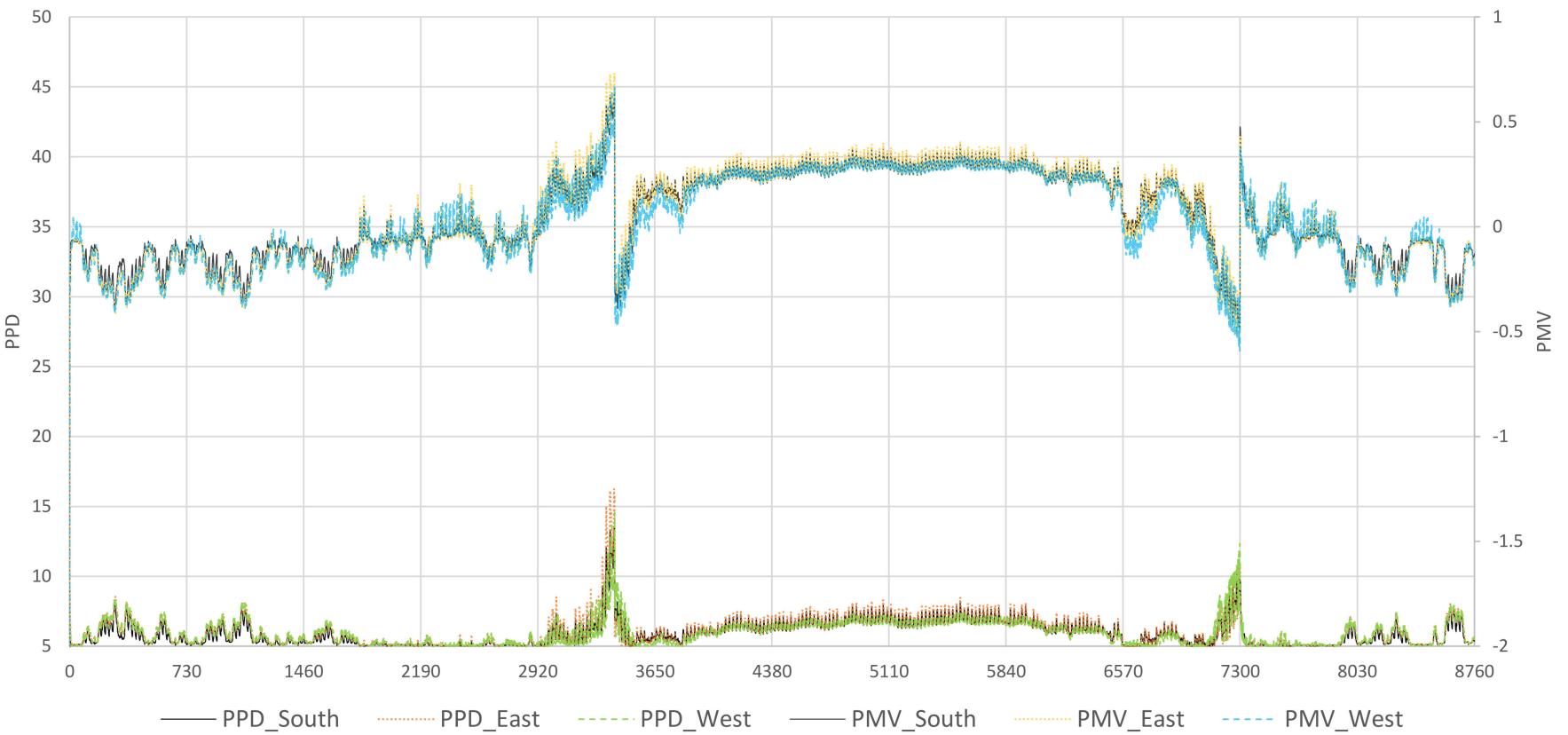

Figure 5. PPD and PMV values for Model 2 in different areas (south, east, and west). 
Model 3

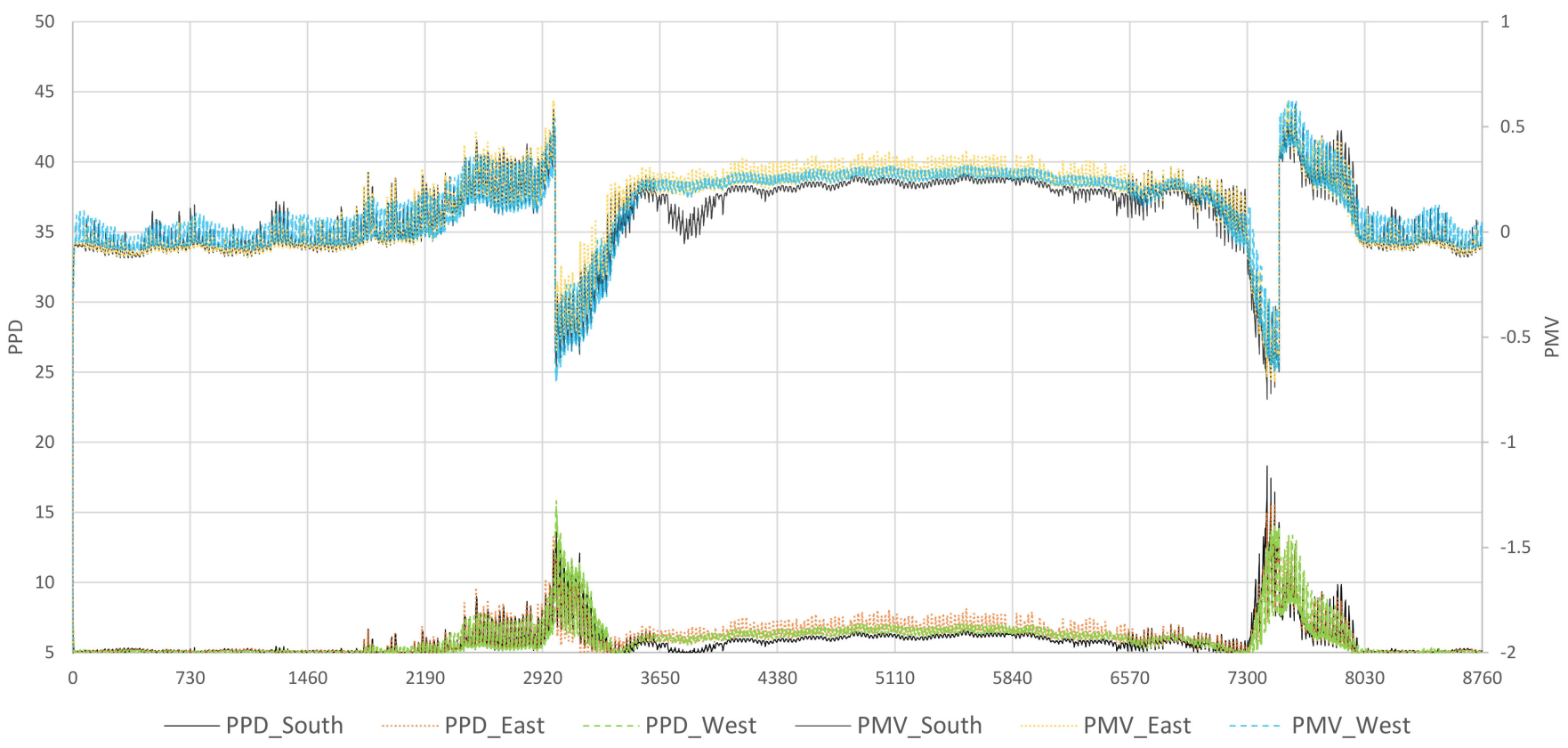

Figure 6. PPD and PMV values for Model 3 in different areas (south, east, and west).

Model 4

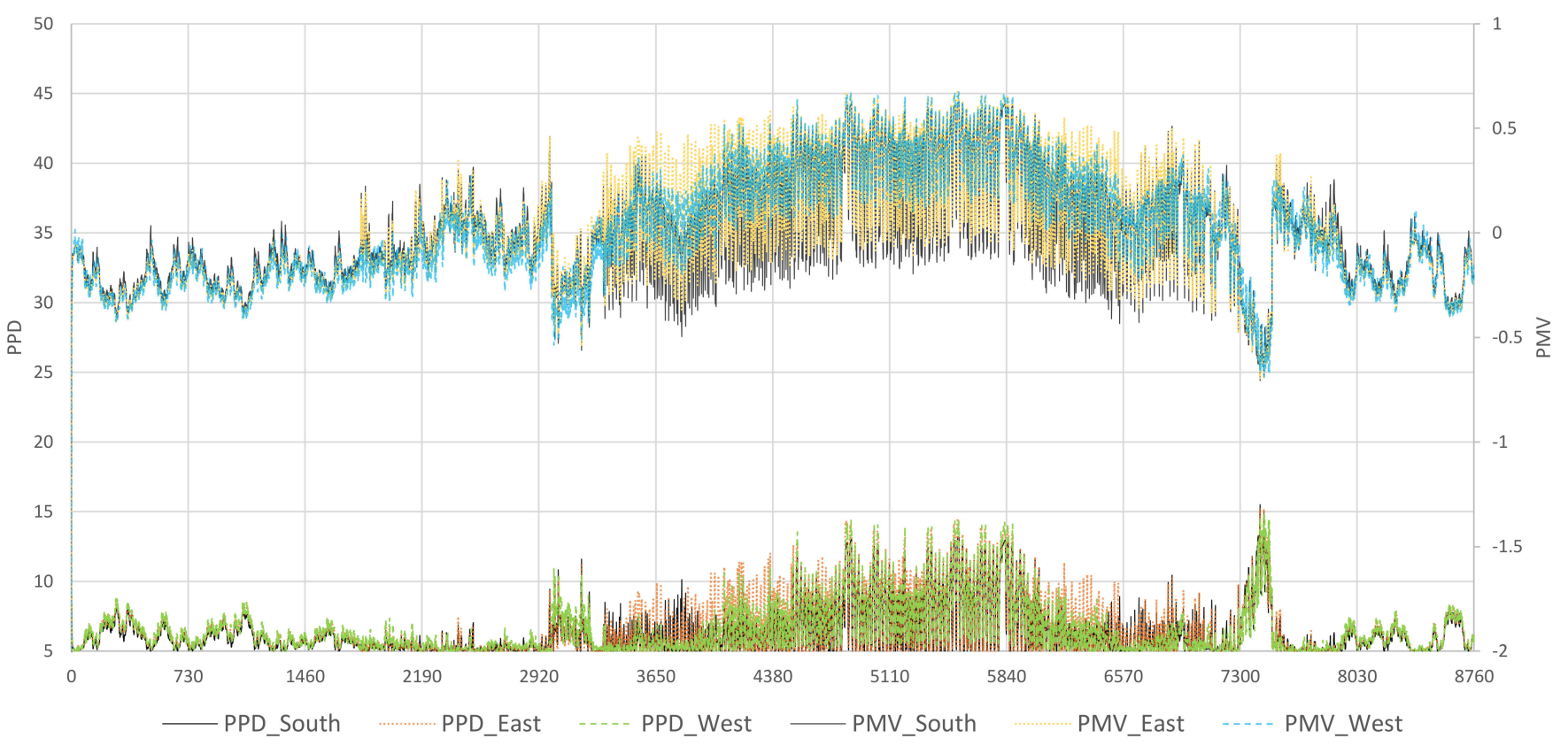

Figure 7. PPD and PMV values for Model 4 using clo 0.7 in cooling season in different areas (south, east, and west).

Table 4. Average PMV values for different areas (south, east, and west) and different models.

\begin{tabular}{ccccc}
\hline & Model 1 & Model 2 & Model 3 & Model 4 \\
\hline South area & -0.19 & -0.03 & 0.15 & -0.19 \\
\hline East area & -0.13 & 0.00 & 0.19 & -0.18 \\
\hline West area & -0.11 & -0.01 & 0.14 & -0.19 \\
\hline
\end{tabular}




\section{Discussion}

The Spanish standard regulation has a specified section about the energy consumption for buildings; then, it is necessary to consider the efficiency and consumption of the heating and cooling system in order to obtain the global energy consumption. For a single house, it is considered to supply electricity and assumed that all the systems will work with it. In addition, a split system for heating and cooling is normal in this kind of building, and it is possible to find low energy consumption systems. The standard system with A+ efficiency is considered with SEER $=5.6$ and SCOP $=4$ in order to obtain the global consumption that for no renewable energy in Valencia, the maximum is $28 \mathrm{~kW} / \mathrm{m}^{2}$ year; Model 2 to Model 4 fulfill this condition. It means that we can fulfill the regulation requirements with a high-efficiency system and the minimum conditions on the envelope; all the extra elements that we have introduced on the project are in order to improve the comfort conditions and reduce the energy consumption.

Thermal comfort is influenced not only by temperature; it is also necessary to consider other factors such as humidity, temperature operative, and air velocity. Analyzing the comfort factor PPD and PMV gives more information in order to decide which solution should be considered, as the energy-efficient consumption can be fulfilled easily with good equipment when the envelope has good insulation. Thermal comfort also depends on people, their clothes, and metabolism rate, so there is a percentage of confidence, which is reflected in PPD values (predicted percent dissatisfied). While the thermal comfort estimated for models showed different performance, in general, a similar behavior was observed in many different areas.

Model 2, developed using minimum requirements Spanish standards regulations regarding insulation, envelope characteristics and infiltration, showed PPD and PMV values that indicate a comfortable indoor environment.

Model 3 was developed in order to reduce energy demand during winter, and it used several of the improvements applied to a previous model (Model 2). Measures considered were the area of the window in the south orientation and the shading device and reinforcement in insulation (10 cm total thickness) on the envelope (walls, ceiling, and floor). This model showed PPD and PMV values that indicate a comfortable indoor environment.

Model 4 was developed in order to reduce the cooling energy demand; natural ventilation was considered, which was applied to a previous model (the model developed in order to reduce energy demand during winter) to see the effect when windows are open under particular conditions. This model, when 0.5 clo was considered, showed an uncomfortable indoor environment in the beginning (May) and the end of the cooling season (October). This effect is probably due to the influence of the ventilation on thermal comfort. When a value of 0.7 clo was considered for this model in the cooling season, then a comfortable indoor environment was obtained for the whole year.

\section{Conclusions}

Analyzing the performance of the house using transient simulation software and considering wind speed and direction allowed calculating the energy demand for the house using real results. This tool enables designing and optimizing the building considering different models. Temperature and humidity sensors have been installed in different areas in order to validate the developed model, allowing knowing the thermal behavior of the building. Afterwards, on the validated model, we analyzed the energy demand of the historical building with its current/updated characteristics, which is named Model 1, adapting into a single-family house, as this is currently the highly demanded typology due to its proximity to the city and the need to protect the natural environment. As a result of the non-isolation of the building, in Model 1, it has been proven that the energy demand is very high with values such as $182.91 \mathrm{kWh} / \mathrm{m}^{2}$ year, which does not comply with the current regulations. As a result, different strategies have been proposed that allow us to reduce the energy demand. The first improvement strategy has allowed us to develop Model 2, which is strictly complying with the points marked in regulations by thermal 
insulation of the enclosure and reducing infiltrations, thereby reducing energy demand by $62.75 \%$ and obtaining a value of $68.14 \mathrm{kWh} / \mathrm{m}^{2}$ year. Other models also have been proposed to reduce the energy demand of heating and cooling systems by modifying the surface of the openings located on the south façade and improving the enclosure insulation, which shows a reduction of demand in Model 3 by $77.33 \%$ compared to Model 1, also introducing the natural ventilation strategies that depend on the use and do not imply any cost on construction. Model 4 shows an annual demand of $32.56 \mathrm{kWh} / \mathrm{m}^{2}$ year and reduces the demand by $82.20 \%$ compared to Model 1 . Parallel to the analysis of the demand, we analyzed the interior comfort of the dwelling according to the use and orientation of different zones. Analyzing the comfort factor PPD and PMV values gives more information in order to decide which solution should be considered, because the energy consumption with good equipment can be fulfilled easily when the envelope has good insulation. In Model 2 and Model 3, the PPD values are below 20\% and the PMV values are showing a comfortable indoor environment. In Model 4, the PPD and PMV values show a comfortable indoor environment throughout the whole year except for the beginning and the end of the cooling season, when a value of 0.5 clo in the cooling season was considered. So, Model 4 has been modified considering a value of 0.7 clo in the cooling season; then, a comfortable indoor environment was obtained. Thermal comfort has different performance for different models, and it is not directly related to energy demand. Thus, to guarantee thermal comfort, it is important to take into account this type of analysis in order to check when and where the focus and the efforts for the measures need to be done.

Occupants' behavior can be considered in models; advantages for these considerations are that these measures do not have any cost for the user.

Author Contributions: Conceptualization, V.P.-A., C.A.-F. and J.-L.V.; methodology, C.A.-F. and J.-L.V.; software, C.A.-F.; validation, C.A.-F.; formal analysis, V.P.-A., C.A.-F. and J.-L.V.; investigation, V.P.-A. and J.-L.V.; writing-original draft preparation, C.A-F. and J.-L.V.; writing-review and editing, V.P.-A., C.A.-F., J.-L.V. and J.C.-C.; supervision, C.A.-F. and J.-L.V. All authors have read and agreed to the published version of the manuscript.

Funding: This research was funded by the Ministry of Science and Innovation (PID2019-108271RB-C33).

Acknowledgments: To Vicent Martí, the owner of the house.

Conflicts of Interest: The authors declare no conflict of interest.

\section{References}

1. D'Agostino, D. Improving Energy Efficiency in Buildings: Challenges and Opportunities in the European Context. In Sustainability through Energy-Efficient Buildings; Shukla, A., Sharma, A., Eds.; Taylor \& Francis, CRC Press: Boca Raton, FL, USA, 2018; pp. 181-209, ISBN 9781315159065.

2. European Commission. Energy Use in Buildings. Available online: https:/ / ec.europa.eu/energy/eu-buildings-factsheets-topicstree/energy-use-buildings_en (accessed on 17 February 2021).

3. Institute for Energy Diversification and Saving-IDAE Project Sech-Spahousec. Analysis of the Energetic Consumption of the Residential Sector in Spain. In Proyecto Sech-Spahousec, Análisis del Consumo Energético del Sector Residencial en España; IDAE: Madrid, Spain, 2016; p. 76.

4. Cuchí Burgos, A.; De La Puerta, I. Diagnóstico de la Rehabilitación en Comunidades Autónomas: Luces y Sombras de un Sector Que No Despega; GTR: Madrid, Spain, 2016; ISBN 978-84-617-4203-5.

5. Ríos Fernández, J.C.; González-Caballín, J.M.; Gutiérrez-Trashorras, A.J. Effect of the climatic conditions in energy efficiency of Spanish existing dwellings. Clean Technol. Environ. Policy 2020, 22, 211-229. [CrossRef]

6. Aguacil, S.; Lufkin, S.; Rey, E.; Cuchi, A. Application of the cost-optimal methodology to urban renewal projects at the territorial scale based on statistical data-A case study in Spain. Energy Build. 2017, 144, 42-60. [CrossRef]

7. Presidencia del Gobierno. Norma Básica de Edificación NBE-CT-79, Sobre Condiciones Térmicas en los Edificios; BOE: Madrid, Spain, 1979.

8. Minisiterio de Fomento Código Técnico de la Edificación (CTE). Real Decreto 732/2019, de 20 de Diciembre, por el que se Modifica el Código Técnico de la Edificación, Aprobado por el Real Decreto 314/2006, de 17 de Marzo; BOE: Madrid, Spain, 2019; pp. 140488-140674.

9. Ministerio de la Presidencia. Gobierno de España Reglamento de Instalaciones Térmicas en los Edificios (RITE); BOE: Madrid, Spain, 2007; pp. 35931-35984. 
10. Ministerio de la Presidencia. Gobierno de España Real Decreto 47/2007. In Procedimiento Básico Para la Certificación de Eficiencia Energética de Edificios de Nueva Construcción; BOE: Madrid, Spain, 2007; Volume 27.

11. Gangolells, M.; Casals, M.; Forcada, N.; MacArulla, M.; Cuerva, E. Energy mapping of existing building stock in Spain. J. Clean. Prod. 2016, 112, 3895-3904. [CrossRef]

12. Martín-Consuegra, F.; de Frutos, F.; Oteiza, I.; Alonso, C.; Frutos, B. Minimal monitoring of improvements in energy performance after envelope renovation in subsidized single family housing in Madrid. Sustainability 2021, 13, 1-26.

13. Mata, É.; Benejam, G.M.; Kalagasidis, A.S.; Johnsson, F. Modelling opportunities and costs associated with energy conservation in the Spanish building stock. Energy Build. 2015, 88, 347-360. [CrossRef]

14. Mata, É.; Sasic Kalagasidis, A.; Johnsson, F. Building-stock aggregation through archetype buildings: France, Germany, Spain and the UK. Build. Environ. 2014, 81, 270-282. [CrossRef]

15. Loga, T.; Stein, B.; Diefenbach, N. TABULA building typologies in 20 European countries-Making energy-related features of residential building stocks comparable. Energy Build. 2016, 132, 4-12. [CrossRef]

16. Sarbu, I.; Pacurar, C. Experimental and numerical research to assess indoor environment quality and schoolwork performance in university classrooms. Build. Environ. 2015, 93, 141-154. [CrossRef]

17. Martinez-Molina, A.; Boarin, P.; Tort-Ausina, I.; Vivancos, J.L. Assessing visitors' thermal comfort in historic museum buildings: Results from a Post-Occupancy Evaluation on a case study. Build. Environ. 2018, 132, 291-302. [CrossRef]

18. Ballarini, I.; Costantino, A.; Fabrizio, E.; Corrado, V. A Methodology to Investigate the Deviations between Simple and Detailed Dynamic Methods for the Building Energy Performance Assessment. Energies 2020, 13, 6217. [CrossRef]

19. Aparicio-Fernández, C.; Vivancos, J.L.; Cosar-Jorda, P.; Buswell, R.A. Energy modelling and calibration of building simulations: A case study of a domestic building with natural ventilation. Energies 2019, 12, 3360. [CrossRef]

20. Martínez-Ibernón, A.; Aparicio-Fernández, C.; Royo-Pastor, R.; Vivancos, J.-L. Temperature and humidity transient simulation and validation in a measured house without a HVAC system. Energy Build. 2016, 131, 54-62. [CrossRef]

21. Pérez-Andreu, V.; Aparicio-Fernández, C.; Martínez-Ibernón, A.; Vivancos, J.L. Impact of climate change on heating and cooling energy demand in a residential building in a Mediterranean climate. Energy 2018, 165, 63-74. [CrossRef]

22. Gregório-Atem, C.; Aparicio-Fernández, C.; Coch, H.; Vivancos, J.L. Opaque ventilated façade (OVF) thermal performance simulation for office buildings in Brazil. Sustainability 2020, 12, 7635. [CrossRef]

23. Kerfah, I.K.; El Hassar, S.M.K.; Rouleau, J.; Gosselin, L.; Larabi, A. Analysis of strategies to reduce thermal discomfort and natural gas consumption during heating season in Algerian residential dwellings. Int. J. Sustain. Build. Technol. Urban Dev. 2020, 11, 45-76.

24. Sarbu, I.; Adam, M. Experimental and numerical investigations of the energy efficiency of conventional air conditioning systems in cooling mode and comfort assurance in office buildings. Energy Build. 2014, 85, 45-58. [CrossRef]

25. Ranjbar, A. Analysing the effects of thermal comfort and indoor air quality in design studios and classrooms on student performance. In Proceedings of the IOP Conference Series: Materials Science and Engineering, Bari, Italy, 5-7 September 2019; Institute of Physics Publishing: Bristol, UK, 2019; Volume 609.

26. ISO. ISO 7730 Ergonomics of the Thermal Environment-Analytical Determination and Interpretation of Thermal Comfort Using Calculation of the PMV and PPD Indices and Local Thermal Comfort Criteria; ISO: Geneva, Switzerland, 2005.

27. Instituto Eduardo Torroja de Ciencias de la Construcción. Catálogo de Elementos Constructivos del CTE; Instituto Eduardo Torroja de Ciencias de la Construcción: Madrid, Spain, 2010.

28. Thirumalai, C.; Vignesh, M.; Balaji, R. Data analysis using box and whisker plot for lung cancer. In Proceedings of the 2017 Innovations in Power and Advanced Computing Technologies (i-PACT), Vellore, India, 21-22 April 2017; pp. 1-6. 